\title{
BIODIVERSITY AND MEDICINAL USES OF GLOBE ARTICHOKE (Cynara scolymus L.) PLANT
}

\author{
Bekheet, S. and V. Sota ${ }^{1}$ \\ Plant Biotechnology Dept., National Research Center, El-Bohouth Str., Dokki, Cairo, Egypt; \\ ${ }^{1}$ Department of Biotechnology, Faculty of Natural Sciences, University of Tirana, Albania
}

\begin{abstract}
Globe artichoke (Cynara scolymus L.) is a vegetable crop native of the Mediterranean basin and it is grown mainly for its immature flower buds. The edible parts of artichoke have important nutrition values to their content of inulin, fibers and minerals. Furthermore, artichoke is recognized as a medicinal plant where leaves and heads are rich source of polyphenolic compounds. It is recommended for the treatment of gallstones, liver disease or damage and poor liver function. The pharmaceutical properties of artichoke are linked to their special chemical composition, which includes high levels of polyphenols such as cynarin, along with its biosynthetic precursor chlorogenic acid. Globe artichoke is characterized by a wide range of biodiversity which represents a prerequisite for genetic improvement. However, there are many factors including biotic and abiotic stresses threatening the genetic resources of globe artichoke. Such factors could result in genetic erosion due to crop failure and loss of cultivars. Therefore, there is a great need to preserve the globe artichoke diversity for future genetic improvement. Because most cultivars are highly heterozygous, maintenance of globe artichoke germplasm in seed form is restricted. Otherwise, conservation in the field presents major drawbacks, which limit its efficacy and threaten the safety of germplasm conserved in this way. The application of biotechnology tools, i.e. plant tissue culture and molecular biology technique can provide reliable methods for supporting the exploitation and conservation of globe artichoke biodiversity. Furthermore, in vitro culture techniques could be used for the controlled production of artichoke secondary metabolites. This article discusses the biodiversity, conservation and nutritional and medicinal aspects of globe artichoke plant.
\end{abstract}

Key words: Biodiversity; Conservation; Globe artichoke; In vitro; Phenolic compounds.

\section{INTRODUCTION}

Globe artichoke (Cynara scolymus L.) is an herbaceous perennial plant belonging to the Asteraceae family which includes three main subspecies: cultivated cardoon (var. altilis DC), globe artichoke (var. scolymus L.) and wild cardoon [var. sylvestris (Lamk) Fiori], that are fully cross-compatible with one another (Rottenberg, 2014). Artichoke is particularly widespread in the Mediterranean Basin, where the climate is characterized by warm summers and mild winters (Leskovar et al. 2013). The economic use of the globe artichoke includes mainly the consumption of the edible immature flower heads, eaten as a fresh, frozen or canned delicacy. The edible portions of the artichoke are then given by the lower portions of the bracts and the receptacle (Conti et al. 2005). The use of the plant is not restricted to its edible part, but also to the leaves, stem and roots that are utilized as sources of: (a) forage for livestock; (b) extraction of inulin; (c) feedstock for the extraction of secondary metabolites; (d) lignocellulosic biomass for energy and paper pulp; (e) seed oil for biodiesel fuel production and (f) alcoholic beverages (Raccuia and Melilli 2004).

Since ancient time globe artichoke has been used in traditional medicine for its recognized therapeutic affects i.e. hepatoprotective, anticarcinogenic, antioxidative, antibacterial, urinative, anticholesterol, glycaemia reduction (Gebhardt 1997, Kraft 1997, Coinu et al. 2007, Fantini et al. 2011). These health-promoting properties are mainly linked to the high content of polyphenolic compounds, which includes mono- and dicaffeoylquinic acids and flavonoids (Wang et al. 2003, Fratianni et al. 2007, Lattanzio et al. 2009, Pandino et al. 2010). In particular, within the caffeic derivatives, chlorogenic acid (3-O-caffeoylquinic acid) is the most abundant component and represents about the 
$39 \%$ of the total caffeoylquinic acid content (Lattanzio et al. 2009). Other major caffeoylquinic acid derivatives found in leaf and head extracts are represented by 1,5-O-dicaffeoylquinic acid (21\% of total caffeoylquinic acids), 3,4-Odicaffeoylquinic acid (11\% of total caffeoylquinic acids) and cynarin or 1,3Odicaffeoylquinic acid (1.5\% of total caffeoylquinic acids) (Lattanzio et al. 1994, 2009). However, it is important mention that, phenolic content of artichoke is strongly related to physiological stages, genotype, plant parts, environmental conditions, agricultural management and post-harvest conditions (Lombardo et al. 2010, Negro et al. 2011, Pandino et al. 2011a, 2011b, 2011c, 2012).

Due to its economic importance, conservation of globe artichoke genetic resources has become an important issue. The main threats to the artichoke genetic resources are the low number of cultivated varieties, compared to the large diversity present originally, which is an index of genetic erosion. Otherwise, successive generations of vegetative propagation have minimized the introgression of genes from other populations. In this respect, the high variability of artichoke seeds, together with difficulties in the distribution and exchange of safe plant material from field genebanks, support tissue culture as the best alternative approaches for germplasm conservation and utilization in this species. In vitro conservation provides protection from pathogen and climatic hazards. In practice, maintenance of plant germplasm in in vitro active collections or slow growth state offers a medium-term storage option. For long-term storage and for the establishment of in vitro base collections, cryopreservation is the most reliable option as well as being cost and space effective. Cryopreservation involves the maintenance of plant propagules at ultra-low temperatures $\left(-196^{\circ} \mathrm{C}\right.$ in liquid nitrogen, $\left.\mathrm{LN}\right)$ : under these conditions, biochemical and most physical processes are completely arrested and plant material can be stored for unlimited periods (Reed 2008). In this context, in vitro techniques have been developed for mediumterm (Bekheet 2007, Tavazza et al. 2012, El Boullani et al. 2017) and long-term (Tavazza et al. 2013) storage of globe artichoke germplasm. On the other hand, in vitro systems of globe artichoke secondary metabolites are considered to be an attractive alternative to classical technologies for its sustainable use. In this context, various strategies have been developed for in vitro accumulation of artichoke secondary compounds such as strain improvement, optimization of culture medium and environments, elicitation, precursor feeding, metabolic engineering and transformation. This article discusses chemical compositions of globe artichoke and their pharmacological importance as well as the biodiversity and conservation of its germplasm.

\section{THE TEXT}

If we consider discussing on artichoke as a whole, we have to task the aspect of chemical constituents, traditional cultivars, propagations and seeds, uses (as foods, herbal tea, liqueur, medicinal researches and genome researches) and agricultural output. Some of the aspects are taken under consideration in the present text as described below-

\section{The origins and biodiversity of globe artichoke}

Globe artichoke is an ancient herbaceous perennial plant originating to the Mediterranean area. Artichoke's ancestor appeared in Mediterranean region was used as food by the ancient Greeks and Romans. Greeks cultivated them on Sicily and called them "kaktos." Further cultivation was performed at Naples in the 9th century and in Muslim Spain and the Maghreb (a region in Northwest Africa, near Egypt) in the medieval period (Bianco 2005). Notaries of the Avignon mention artichokes in the 16th century and talk about them as about luxury and aphrodisiac. At about the same time, the Dutch brought artichokes to England. New World saw artichokes for the first time in the 19th century (Sonnante et al. 2007). The spread of globe artichoke germplasm was probably made by seed, which was much easier to transport than vegetative materials. After World War II, the cultivation of globe artichoke was 
neglected, but, in recent years, experiments have been conducted to adapt modern breeding and propagation technologies for the production of new globe artichoke cultivars that grow at higher latitudes than those typically recommended for this species. The strategies used included the introduction of seed-propagated cultivars, together with the modernization of cultivation methods in order to acclimatize plants to more stressful environmental conditions (Cardarelli et al. 2005). As regard globe artichoke production, Italy, Spain, and France are the top European artichoke producers.

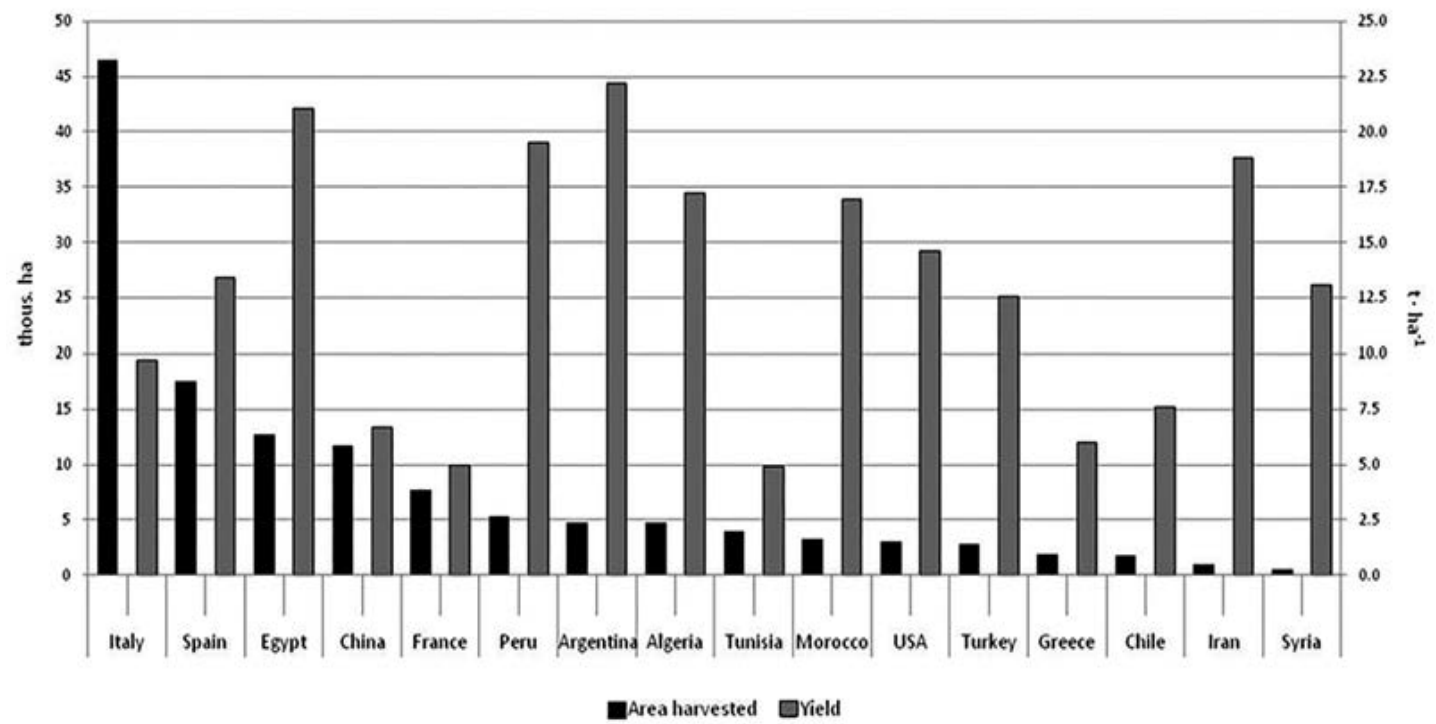

Fig.1. Yield and cultivating area of globe artichoke in the most important production regions in the world (FAO 2017).

The United States is the ninth major artichoke producer. Here, the state of California contributed nearly $100 \%$ of the US crop of which nearly $80 \%$ is grown in the Monterey County. North African countries like Egypt, Morocco, and Algeria also contribute significantly towards the global artichoke production. China is the only Asian country that features in the list of top 10 artichoke producing nations in the world. The most important production regions of globe artichoke in the world are illustrated in Fig. (1). Among Mediterranean countries, Italy, Egypt, and Spain account for $55.4 \%$ of the total area planted with artichoke worldwide and $58.2 \%$ of the total harvest (FAO 2015). It's worth to mention that, Italy represents the richest globe artichoke primary cultivated gene pool with many distinct varietal groups well adapted to different local environments and consumers (Lanteri et al. 2004). In this respect, Apulia region (southern Italy) accounts for 33\% of the total Italian production and harbors many artichoke varieties representing an inestimable source of germplasm (Ciancolini et al. 2012).

Genetic diversity and structure of the gene pool of globe artichoke plant have been shaped and greatly altered by natural and human selection, clonal propagation, and spatiotemporal exchange and movement of germplasm. As far as we know, the gene pool of artichoke is organized into four varietal types, 'Spinoso', 'Violetto', 'Romanesco', 'Catanese', and based on physical characteristics of the main flowering head. Many populations of each type are still grown in various geographical districts, where they are usually named according to the locality of cultivation. Despite the high level of within population genetic variation present, most of the populations could be genetically differentiated from one another due to farm fragmentation or adaptation to local climatic conditions. However, the total number of globe artichoke genotypes cannot be easily determined and, even if 100-120 genotypes are at present estimated, only 11-12 can be considered more important for their commercial interest (Mauro et al. 2009). Due to the great genetic variability found within several cultivated populations of globe 
artichoke, the term 'varietal type' seems more appropriate than 'variety' to define the accessions of germplasm (Lanteri et al. 2004). Indeed, globe artichoke varieties are encompassing a wide range of sizes, shapes and colors (Table 1) existing in the different growing countries. These varieties have been developed by continuous selection performed by growers mainly to improve crop yield and quality. The following main characteristics are used to group globe artichoke cultivars on the basis of their morphological traits: midrib thickness, main stem diameter and time of beginning elongation, intensity of leaf lobing, central flower head length, diameter and shape in longitudinal sections, outer bract color and thickness at the base, the presence or absence of spines, and the number of lateral heads on the main stem (Cravero et al. 2007).Tightness and head color are the most important determinants of quality because consumers are sensitive to these traits (Cravero et al. 2005). However, the analysis of genetic variability of globe artichoke varieties using morphological traits creates difficulties. Most germplasm cannot be clearly separated into discrete categories because of extensive variations in phenology, morphology, chemical composition, and yield potential (Lanteri and Portis 2008). In this respect, six artichoke cultivars grown in Murcia (Spain) were evaluated to ascertain their optimum commercial use by determining their physical, chemical and biochemical parameters (production yield, shape, size, moisture and color of their heads, respiration rate, phenolic content, enzymatic activities and browning potential) (Garcia-Martínez et al. 2017). The Physical parameters, such as morphology, moisture and color of heads, and plant productivity varied according to cultivar.

\section{Molecular characterization and genome analysis}

Germplasm identification is generally done in three ways: morphological comparisons with prior written descriptions; consultation with taxonomists or crop specialists; and molecular analysis. In globe artichoke, morphological characteristics, such as head shape and diameter, leaf shape, and bract shape, are mainly affected by environmental conditions. The complementarity of morphological and molecular analyses can contribute to the accurate identification and classification of landraces in the management of globe artichoke genetic resources for in situ and ex situ conservation as well as for use in breeding programs (Crino et al. 2008, Lo Bianco et al. 2011). For molecular characterization, random amplified polymorphic DNA (RAPD) and amplified fragment length polymorphism (AFLP) markers have demonstrated to be effective for analyzing genetic variation, genotypes identification, and population and phylogenetic studies in plant species. In this respect, genetic variation in five populations of 'Spinoso sardo', the most widely grown and economically important artichoke cultivar in Sardinia (Italy) was measured using RAPD (Lanteri et al. 2001). Analysis of molecular variance gave highly significant differences between populations ( $28.1 \%$ of the total genetic diversity); substantial withinpopulation variation was detected (71.8\% of total genetic diversity). Lanteri et al. (2004) analyzed genetic relatedness among 118 globe artichoke accessions including 89 varietal types by means of AFLP markers. Seven populations were identified, of which three were of the spiny type 'Spinoso di Palermo' and four of the non-spiny type 'Violetto di Sicilia'. A significant genetic differentiation between spiny and non-spiny types was found. Most of the populations were genetically distinct, as a result of farm fragmentation and adaptation to local pedo-climatic conditions. Likewise, a total of 32 accessions of cultivated (Cynara cardunculus L. var. scolymus (L.) Fiori), three of wild (Cynara cardunculus var. cardunculus L.) artichoke and two of cultivated cardoon (Cynara cardunculus var. altilis L.) were analyzed in order to study genetic variation and relationships within the species, using RAPD markers (Sonnante et al. 2002). An intra-accession analysis using 4 varieties and 8 polymorphic primers revealed that no RAPD variation was detected among individuals.

In order to develop a crossing strategy for future breeding of globe artichoke, a framework of linkage relationships should be established to allow the identification and localization of genes that 
control important yield traits or resistance against pathogens. The establishment of linkage relationships between molecular marker loci represents the initial step in the identification of the chromosomal regions carrying genes relevant for marker assisted breeding application. In general, advances in DNA sequencing technology have greatly simplified the acquisition of medium-sized and even large genomes.

Table 1. Variability in head morphology of nine globe artichoke varieties.

\begin{tabular}{|c|c|}
\hline Variety & Head description \\
\hline Omaha & $\begin{array}{l}\text { The dense and rotund Omaha artichoke (up to six inches wide) owes its striking appearance to its } \\
\text { sharply tapered red-and-green leaves. It is less bitter than many artichoke varieties. }\end{array}$ \\
\hline Mercury & $\begin{array}{l}\text { The petite Mercury, with its red-violet hue and distinctive rounded top, is sweeter than many other } \\
\text { artichokes and is usually three and a half inches in diameter. }\end{array}$ \\
\hline Siena & $\begin{array}{l}\text { The oblong Siena, about four inches in diameter. Slow to mature and still grown in relatively small } \\
\text { quantities, this small artichoke usually weighs less than a pound and has a heart tender enough to be } \\
\text { eaten raw. }\end{array}$ \\
\hline Baby Anzio & Light red and only roughly one inch in diameter when fully grown. \\
\hline Chianti & $\begin{array}{l}\text { The chianti, a classically shaped, four-inch-wide green artichoke with a touch of maroon on the } \\
\text { leaves. }\end{array}$ \\
\hline Big Heart & It is endowed with a large, fleshy base and weighs in at over a pound. \\
\hline $\begin{array}{l}\text { Green } \\
\text { Globe }\end{array}$ & $\begin{array}{l}\text { The green globe has a buttery-tasting heart and bottom and an ample amount of meat at the base of } \\
\text { the petals. This artichoke, which ranges in size from three to five inches in diameter and is } \\
\text { traditionally cultivated as a perennial. }\end{array}$ \\
\hline King & $\begin{array}{l}\text { The blocky and vividly colored king has distinctive green spots at the tips of the bracts. Usually four } \\
\text { inches in diameter and weighs more than a pound in peak season }\end{array}$ \\
\hline Fiesole & $\begin{array}{l}\text { The two-inch-wide Fiesole artichoke has a fruity flavor and a deep wine color that does not fade with } \\
\text { cooking. }\end{array}$ \\
\hline
\end{tabular}

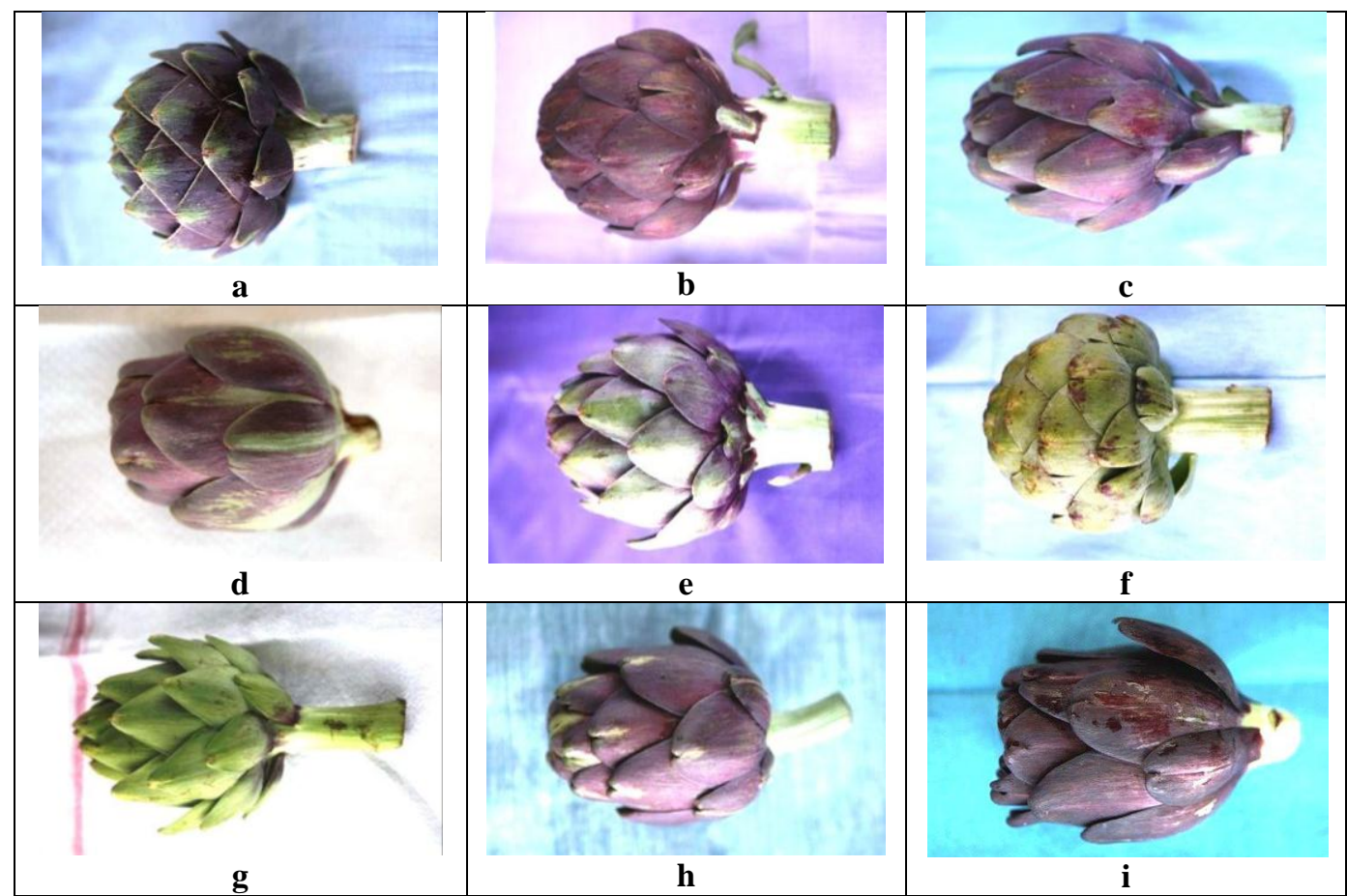

Fig. 2. Varieties of globe artichoke: a. Omaha; b. Mercury; c. Siena; d. Baby Anzio; e. Chianti; f. Big Heart; g. Green Globe; h. King; and i. Fiesole. (Source: August 4, 2008 - https://www.saveur.com/gallery/Artichoke-Varieties).

Little researches have been conducted on the genome sequencing of globe artichoke. The first linkage map of globe artichoke, based on AFLP, microsatellite-AFLP (M-AFLP), and sequence-specific 
amplified polymorphism (S-SAP) markers, was generated by Lanteri et al. (2006). Later on, Portis et al., (2009) report on the construction of the first linkage maps in globe artichoke by applying a combination of PCR-based markers using Fl population of 94 individuals produced by crossing a late-maturing, nonspiny type ('Romanesco C3') and an early-maturing spiny type ('Spinoso di Palermo'). In this respect, Bulked Segregant Analysis (BSA) and Sequence-related amplified polymorphism (SRAP) were used to detect molecular markers linked to the color head and precocity of production of globe artichoke (Martin et al. 2008). One band/marker that was detected may be linked to the green colour head and the other band/marker may be associated with precocity in head production. Lanteri et al. (2006) reported two SSR markers linked to spiny bracts. Recently, the globe artichoke genome sequence has been assembled into some 13,000 scaffolds, which have been assigned to the 17 chromosomes (Scaglione et al. 2016).

\section{Conservation of globe artichoke genetic resources}

Conservation of globe artichoke genetic resources is important not only to preserve the good quality cultivars but also to ensure future access to valuable genes for plant improvement programs. While the abundant in situ biodiversity represents an invaluable genetic resource for breeders, industry, and consumers, at the same time, it is imperative to find a way to restore and maintain a sanitary status compatible with the conservation of such biodiversity. In situ conservation is one of two possible strategies to conserve the artichoke germplasm. The significant advantages to in situ conservation are conservation genetic material and the processes that give rise to diversity. However, ex situ conservation of germplasm is achieved traditionally through different living collections in the field integrated with seed collections. Seed bank is the most widely method used for conserving plant genetic resources. It is usually safer, cheaper and more convenient to conserve genetic resources as seeds than by any other method. But most of the globe artichoke cultivars are highly heterozygous. Therefore, when they have been propagated by seed, the yield of their progeny is frequently different from that of the parental generation. However, some seeded varieties such as Emerald, Adonis and Imperial Star have recently been developed in artichoke breeding programs in Spain, France and the USA (Welbaum 1994). The main problems with seeded artichokes are the lack of uniformity because the plant is cross-pollinated and highly heterozygous. So, maintenance of globe artichoke germplasm in seed form is restricted due to their heterozygosity and segregation. At the present, vegetative conservation with the use of offshoots, underground shoots with apical and lateral buds, and from stumps, is the most common used in conserving globe artichoke germplasm (Morello et al. 2005). This vegetative method is not very specialized and presents a high percentage of plant losses. In terms of the health status of the plants obtained in this manner, vegetative propagation is quite problematic, as the risk of transmission of diseases is very high. So, field conservation of globe artichoke usually enunciated with spread of diseases and develops a phytopathogenic situation which is hard to control. In practice, genotypes are often labeled with the name of their place of cultivation without any study on their genetic identity and characterization or even on their discrimination with other genotypes grown in nearby areas. In spite of its economic importance, conservation of globe artichoke germplasm has not been extensively established. It is, therefore, of paramount importance to develop techniques ensuring optimal storage and rapid multiplication.

Tissue culture in combination with molecular biology techniques are of great interest for collecting, multiplication and storage of plant germplasm. In vitro technologies have had a major impact on the ex situ conservation of plant genetic resources and provides an excellent means of mediating international germplasm exchange. In practice, in vitro storage offers several advantages over field collections because of minimal spatial and maintenance requirements. Moreover, propagation potential of stored cultures is greater and pests and diseases are avoided. Furthermore, quarantine regulations more readily allow in vitro cultures rather than whole plants or cuttings, which could harbor insects, mites, or 
diseases. In this context, different in vitro conservation methods are employed, depending on the storage duration requested. For short- and medium-term storage, the aim is to reduce growth and to increase the intervals between subcultures. For these purposes, a variety of approaches have been used separately and in combination to reduce the growth rates of in vitro plant tissue and the most successful strategies have involved temperature reductions. For long-term storage, cryopreservation, i.e. storage at ultra-low temperature, usually that of liquid nitrogen $\left(-196^{\circ} \mathrm{C}\right)$, is the only current method. At this temperature, all cellular divisions and metabolic processes are stopped (Engelmann 2010). Indeed, propagation of globe artichoke by tissue culture offers an alternative method to produce large, homogeneous and disease-free populations, enabling in vitro storage of its selected genotypes. In this respect, Ancora et al. (1981) and Morone-Fortunato et al. (2005) developed in vitro techniques for micropropgation and short term conservation of Romanesco globe artichoke. Bedini et al. (2012) optimized in vitro cultures of four Tuscan globe artichoke cultivars i.e., Terom, Violetto di Toscana, Chiusure and Empolese. Moreover, in vitro med-term storage of globe artichoke cv. Balady (Egyptian local cultivar) was recognized (Bekheet 2007). Shoot bud cultures were stored under aseptically conditions at $5^{\circ} \mathrm{C}$ or osmotic stress. The results indicated that the storage at the low temperature was obviously effective compared with storage on medium contained osmotic stress agents. Furthermore, a simple and efficient procedure for the cryopreservation of artichoke shoot tips, cultivars 'Grato 1' and 'Campagnano' based on vitrification/one-step cooling, was reported (Tavazza et al. 2013) (Fig. 2). The best survival percentage of cryopreserved shoot tips was $61 \%$ for 'Gratol' and $55 \%$ for 'Campagnano' cultivars. They also reported that cryopreserved shoot tips developed directly into plantlets proved to be stable in terms of chromosome numbers.

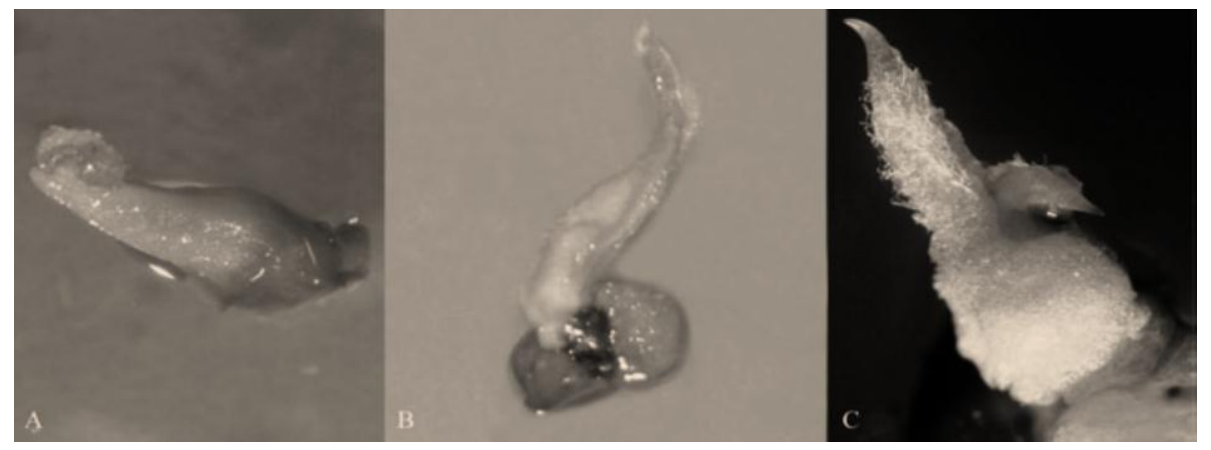

Fig. 3. Recovery of cryopreserved globe artichoke shoot tips. (A) Tissue proliferation at the top of a surviving shoot tip 1 week after rewarming; $(\mathrm{B}, \mathrm{C})$ regrowth of a frozen shoot tip after 8 weeks of culture.

Nutritional value and therapeutic properties of globe artichoke

The economic use of globe artichoke is focused on the consumption of the edible immature flower heads (capitula), commonly referred to as 'heads', eaten as a fresh, canned or frozen vegetable, and recently, demand has been increased because of its reputation as a health food. Approx. 35-55\% of the fresh weight of each globe artichoke head is composed of the tender inner bracts and the receptacle, commonly known as the 'heart'. From a nutritional point of view, globe artichoke is considered as very healthy and nutritious. It is a rich source of minerals (Romani et al. 2006), vitamin C (Gil-Izquierdo et al. 2001), and polyphenols (Brat et al. 2006). Inflorescence bracts are also a promising source of anthocyanins (Schutz et al. 2006), but the anthocyanin profile seems to be highly dependent on cultivar and is directly related to the color of the outer inflorescence bracts. Anthocyanin pigments, besides their health-promoting properties, play an important role in the appearance of food plants and therefore in food acceptance by consumers. It's worth to mention that the presence of caffeoylquinic esters in artichoke tissues is responsible for the appearance of browning phenomena which occur through 
enzymatic oxidation of ortho-dihydroxyphenolic substrates by polyphenol oxidase (PPO, EC 1.14.18.1) or to formation of iron-chlorogenic acid complexes (Lattanzio 2003). However, the particular determinants of the nutritional value of the globe artichoke head are highly variable and depend on the region and cultivation technology, the cultivar, and of course, the analytical methodology used (Sekara et al. 2015). Besides the immature flower heads, the fleshy and developed artichoke root system could be used as a source of inulin. Inulin is an oligosaccharide known to have pre-biotic effects through enhancing the activity of bifidobacteria and lactic acid bacteria in the large intestine, with positive effects on bowel habits. Inulin also increases the absorption of $\mathrm{Ca}$, has positive effects on lipid metabolism, and has anti-cancer properties (Lopez-Molina et al. 2005, Sonnante et al. 2007, Lattanzio et al. 2009). Inulin has also been recognized as a beneficial food ingredient since it is used in yoghurt and ice cream preparations (Raccuia and Melilli 2004). Currently, commercially available inulins are obtained mainly from chicory, Jerusalem artichoke, and dahlia. Artichoke inulin presents similar physico-chemical properties to high performance chicory inulin but an even higher degree of polymerization, which makes artichoke inulin desirable for applications in the food industry (Lattanzio et al. 2009). The inulin yield of artichoke depends on genotype, harvesting date, environmental conditions and extraction processes. Generally, the accumulation of inulin is enhanced by conditions that increase the efficiency of photosynthesis such as a long photoperiod (Raccuia and Melilli 2010).

Globe artichoke is a dietary and medicinal plant species with a long tradition of use dating back to the ancient Egyptians, Greeks, and Romans (de Falco et al. 2015). In folk medicine, many parts of globe artichoke have been widely used as astringent, blood cleanser, cardiotonic, detoxifier, digestive stimulant, diuretic and hypoglycaemic (Lattanzio et al. 2009). Moreover, artichoke leaf extracts were proved to have anticarcinogenic, antioxidative, anti-inflammatory, antibacterial, anti-HIV, bileexpelling, and urinative activities (Martino et al. 1999, Bundy et al. 2008). In this respect, artichoke dry extracts are currently commercialized as drugs mainly for treatment of liver diseases: these include Cynara (200 mg of artichoke extract; Vesta Pharmaceuticals, Inc.), Artichoke $500 \mathrm{mg}$ (artichoke leaf extract; Jarrow Formula, Inc.), Artichoke (artichoke leaf extract containing $0.3 \%$ flavonoids expressed as luteolin-7-O-glucoside and $2.5 \%$ caffeoylquinic acid expressed as chlorogenic acid, Indena S.p.A.), CINARAN (artichoke flowering head extracts containing 13-18\% of caffeoylquinic acids, Indena S.p.A.) among others (Llorach et al. 2002). The variable therapeutic functions cannot be attributed to a single active compound; however it could be due to the presence of several bioactive components which generate synergistic pharmacologic effects. As aforementioned, the dried leaves of artichoke have been used for their choleretic and hepatoprotective activities that are often related to the cynarin content. In various pharmacological test systems, artichoke leaf extracts have shown hepatoprotective (Adzet et al. 1987), antioxidative, anti-HIV, bile-expelling, and urinative activities (Gebhardt 1997) as well as the ability to inhibit cholesterol biosynthesis and LDL oxidation (Englisch et al. 2000). Among the most relevant biological functions, antitumour activity was demonstrated in vitro for globe artichoke triterpenes (Yasukawa et al. 2010).

A renewed interest has been observed in globe artichoke as a source of polyphenols, a heterogeneous class of secondary metabolites characterized by various healthy properties. The well-documented beneficial properties of artichoke polyphenols are mainly related to chlorogenic acid as a free radical scavenger and to dicaffeoylquinic acids as anti-inflammatory agents (Rivelli et al. 2010). Indeed, the pharmacologic properties of artichoke polyphenols are well documented in several in vitro and in vivo studies. The choleretic activity (increased biliary flux with elimination of cholesterol) of both chlorogenic acid and cynarin has been demonstrated in several clinical trials (Kirchhoff et al., 1994). Moreover, positive in vitro and in vivo effects of the artichoke polyphenols on low-density lipoprotein oxidation inhibition were reported by D'Antuono et al. (2015) and Coinu et al. (2007). Likewise, the 
antioxidant activity of the artichoke was evaluated based on its potential as a scavenging the ABTS radical (Jun et al. 2007). The results showed the antioxidant activity of artichoke which has a close relationship with the total flavonoid content.

The most abundant polyphenols in the artichoke are 5-caffeoylquinic acid, also known as chlorogenic acid and dicaffeoylquinic acids. Dicaffeoylquinic acids are present in artichokes as different isomers; the primary isomer is 1,5-dicaffeoylquinic acid, followed by the 3,4-, 3,5-, and 4,5-isomers (Moglia et al. 2008). Another widely known substance found in artichoke extracts is 1,3dicaffeoylquinic acid (cynarin), which is a product of the isomerization of 1,5-dicaffeoylquinic acid in warm aqueous media (Slanina et al. 2001). The artichoke leaves include up to $2 \%$ phenolic acids with mono-and dicaffeoylquinic acids, primarily chlorogenic acid, cynarin, and caffeic acid and also up to 0.1-1\% flavonoids (Zhu et al. 2004). Table (2) shows the biological activity of the isolated caffeoylquinic acids and flavonoids that are responsible of the pharmaceutical effects including antioxidant, vasorelaxant, antibacterial, anti-hyperlipidemic, hepatoprotective and chemopreventive.

Table 2: Biological activity of the isolated phenolic compounds of globe artichoke.

\begin{tabular}{|c|c|c|c|}
\hline \multicolumn{2}{|c|}{ Compounds } & Activity & References \\
\hline \multirow{11}{*}{ 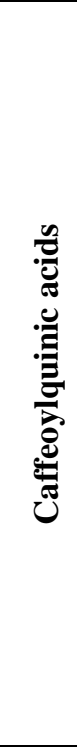 } & $\begin{array}{l}\text { Chlorogenic acid } \\
\text { (common: 3-O- } \\
\text { caffeoylquinic acid; } \\
\text { IUPAC: 5-O- } \\
\text { caffeoylquinic acid). }\end{array}$ & $\begin{array}{l}\text { Hepato protective, antioxidant and } \\
\text { anticarcinogenic. }\end{array}$ & $\begin{array}{l}\text { Gonthier et al. (2003). } \\
\text { Perez-Garcia } \text { et al. (2000). } \\
\text { Garbetta et al. (2014). } \\
\text { Sato } \text { et al. (2011). } \\
\text { Pandino et al. (2011a). }\end{array}$ \\
\hline & \multirow{4}{*}{$\begin{array}{l}\text { Cynarin }(1,3- \\
\text { Dicaffeoylquinic acid }) .\end{array}$} & Hepato protective. & Adzet et al. (1987). \\
\hline & & Antioxidant. & $\begin{array}{l}\text { Wang et al. (2003). } \\
\text { Perez-Garcia et al. (2000). }\end{array}$ \\
\hline & & Anti-HIV. & Robinson et al. (1996). \\
\hline & & Choleretic, anticholestatic, diuretic. & Gebhardt $(2000,2001)$. \\
\hline & 3,4-Dicaffeoylquinic acid. & Anti-influenza viral activity. & Takemura et al. (2012). \\
\hline & 3,5-Dicaffeoylquinic acid. & Antioxidant and anti-apoptotic. & $\begin{array}{l}\text { Zha et al. (2007). } \\
\text { Fritsche et al. (2002). }\end{array}$ \\
\hline & \multirow[t]{4}{*}{ 1,5-Dicaffeoylquinic acid. } & Protection of astrocytes from cell death. & Cao et al. (2010). \\
\hline & & $\begin{array}{l}\text { Prevention of neuron apoptosis in } \\
\text { Alzheimer's disease. }\end{array}$ & Xiao et al. (2011). \\
\hline & & Anticarcinogenic. & Clifford (2000). \\
\hline & & Antioxidant. & Garbetta et al. (2014). \\
\hline \multirow{13}{*}{$\frac{n}{0}$} & \multirow[t]{6}{*}{ Luteolin } & Anticholestatic, choleretic. & Gebhardt $(1998,2000,2001)$. \\
\hline & & Antioxidatant. & $\begin{array}{l}\text { Pandino et al. (2011a), Perez- } \\
\text { Garcia et al. (2000). }\end{array}$ \\
\hline & & Antimicrobial activity. & Zhu et al. (2004). \\
\hline & & Vasorelaxant. & Rossoni et al. (2005). \\
\hline & & Inhibition of lipid peroxidation. & Brown and Rice-Evans (1998) \\
\hline & & Inhibition of multidrug-resistant. & Nissler et al. (2004). \\
\hline & $\begin{array}{l}\text { Cynaroside (luteolin 7-O- } \\
\text { glucoside) }\end{array}$ & $\begin{array}{l}\text { Hepato protective, anticholestatic, } \\
\text { choleretic }\end{array}$ & $\begin{array}{l}\text { Adzet et al. (1987); Gebhardt } \\
\text { (1998). }\end{array}$ \\
\hline & & Inhibition of lipid peroxidation & Brown and Rice-Evans (1998). \\
\hline & $\begin{array}{l}\text { Scolymoside (luteolin 7- } \\
\text { O-rutinoside) }\end{array}$ & Anti-hyperlipidemic & Shimoda et al. (2003). \\
\hline & Apigenin & Vasorelaxant & Rossoni et al. (2005). \\
\hline & & Antioxidant & Garbetta et al. (2014). \\
\hline & & Chemopreventive agent & Shukla and Gupta (2010). \\
\hline & & Antibacterial & Aljancic et al. (1999). \\
\hline
\end{tabular}


The growing importance of globe artichoke as a source of pharmaceuticals has raised new issues that all products have to face and hence the necessity of contemporaneous development of new technologies demanded. Plant cell and tissue cultures are the most applied biotechnology that can offer bioactive compounds of artichoke for pharmaceutical industries. In this respect, an artichoke callus culture method was established by Trajtemberg et al. (2006). This culture produced a total caffeoylquinic acid level of $0.49 \%$ (dry wt.). In vitro callus-induction of globe artichoke as a system for the production of caffeoylquinic acids was also achieved by Menin et al. (2013). For this purpose, combinations of media supplements (e.g., phytohormones, absorbers of polyphenols, and inhibitors of polyphenol oxidase), along with various light regimes, and three different genotypes of globe artichoke were investigated. Elaborated in vitro culture protocol which resulted in a high frequency of callus induction was established within two weeks. Quantitative HPLC analysis revealed that, as in globe artichoke leaves, the predominant phenolic esters present in callus were mono- and di-caffeoylquinic acids (diCQA). The concentration of diCQA was three to five-fold higher in calli than in leaves. In addition, exposure of calli to UV-C light further enhanced the levels of CQAs. Otherwise, in vitro hypolipidemic effects of extracts of globe artichokes callus cultures were studied by Bekheet et al. (2014). The results proved that globe artichoke extract showed more potent hypolipidaemic and antioxidant effects than the milk thistles extract. Pandino et al. (2017) investigated accumulation and antioxidant activity of phytochemicalsin in suspension cultures of globe artichoke. They established an anthocyanin-producing cell culture and determined the optimal time to harvest cell suspension cultures in order to maximize their biochemical potential and antioxidant activity. Optimum production of polyphenols was achieved on day 25 of culture. Based on the results, they reported that cell suspension of globe artichoke could represent a potential source of bioactive compounds with high antioxidant properties for industrial applications.

Recently, Farhan et al. (2018) obtained two types of callus (friable and compact) from leaves of in vitro grown seedlings of globe artichoke. They mentioned that the extract of friable callus produced $0.858 \mathrm{mg} / \mathrm{g}$ of total phenolic compounds. However, El-Bahr et al. (2018) investigated the accumulation of cynarin in ethephon treated callus cultures of globe artichoke. They found that callus treated with ethephon ( $\left.45 \underline{\mathrm{ul}} \mathrm{L}^{1}\right)$ showed increase in cynarin content.

On the other hand, results of researches prove that transfer of some DNA (T-DNA) oncogenes, such as the rolB and rolC genes of $A$._rhizogenes and the $6 b$ gene of $A$. tumefaciens, affect the biosynthesis of secondary metabolites in transformed plant cells (Gális et al. 2004, Bulgakov 2008). Transformation with the rolC gene is especially useful in those cases where different methods commonly used to increase secondary metabolite production (cell selection, elicitor treatments, and addition of a biosynthetic precursor) only slightly enhance cell productivity. The first successful artichoke transformation was performed with an Agrobacterium tumefaciens Ag10 01-124 strain harboring the binary vector pCAMBIA 2301 (Menin et al. 2012). Likewise, Vereshchagina et al. (2014) transformed artichoke with the rolC gene, which is a known inducer of secondary metabolism. High performance liquid chromatography with UV and high resolution mass spectrometry (HPLC-UV-HRMS) revealed that the predominant metabolites synthesized in the transgenic calli were 1,5-dicaffeoylquinic acid, 3,4dicaffeoylquinic acid, and chlorogenic acid. The overall production of these metabolites was three times higher than that of the corresponding control calli. To date few studies on phenylpropanoid biosynthetic pathway have been performed in globe artichoke. In this context, Comino et al. (2009) isolated a gene sequence encoding a hydroxycinnamoyltransferase (HCT), involved in the synthesis of chlorogenic acid. A phylogenetic analysis revealed that their sequences belong to one of the major acyltransferase groups (anthranilate N-hydroxycinnamoyl/benzoyltransferase). Otherwise, Moglia et al. (2009) isolated and characterized a full-length cDNA and promoter of a globe artichoke p-coumaroyl ester 3'-hydroxylase 
(CYP98A49), which is involved in both chlorogenic acid and lignin biosynthesis. Phylogenetic analyses demonstrated that this gene belongs to the CYP98 family.

\section{REFERENCES}

Adzet, T., J. Camarasa and J. C. Laguna. 1987. Hepatoprotective activity of polyphenolic compounds in isolated rat hepatocytes from Cynara scolymus against $\mathrm{CCl} 4$ toxicity: in isolated rat hepatocytes. $J$. Nat. Prod. 50(4): 612-617.

Aljancic, I., V. Vajs and N. Menkovic. 1999. Flavones and sesquiterpene lactones from Achillea atrata subsp. multifida: antimicrobial activity. J. Nat. Prod. 62: 909-911.

Ancora, G., M. L. Belli-Donini and L. Cuozzo. 1981. Globe artichoke plants obtained from shoot apices through rapid in vitro micropropagation. Sci. Hortic. 14(13): 207-21.

Bedini, L., M. Lucchesini, F. Bertozzi and A. Graifenberg. 2012. Plant tissue cultures from four Tuscan globe artichoke cultivars. Cent. Eur. J. Biol. 7(4): 680-689.

Bekheet, S. A. 2007. In vitro preservation of globe artichoke germplasm. Plant Tissue Cult. Biotech. 17(1): $1-9$.

Bekheet, S. A., M. K. El-Bahr, S. A. Ali and M. A. Hamed. 2014. Callus production of Globe artichoke and Milk thistle: In vitro hypolipidemic and antioxidant activities. World J. Pharma. Res. 3(4): 1-17.

Bianco, V. V. 2005. Present situation and future potential of artichoke in the Mediterranean basin. Acta Hortic. 681: 39-55.

Brat, P., S. George, A. Bellamy, L. D. Chaffaut, A. Scalbert and L. Mennen. 2006. Daily polyphenol intake in France from fruit and vegetables. J. Nutr. 136: 2368-2373.

Brown, J. E. and C. Rice-Evans. 1998. Luteolin-rich artichoke extract protects low-density lipoprotein from oxidation in vitro. Free Radic. Res. 29:247-255.

Bulgakov, V. P. 2008. Functions of rol genes in plant secondary metabolism. Biotechnol. Adv. 26:318-324.

Bundy, R., A. F. Walker, R. W. Middleton, C. Wallis and H. C. Simpson. 2008. Artichoke leaf extract (Cynara scolymus) reduces plasma cholesterol in otherwise healthy hypercholesterolemic adults: a randomized, double blind placebo controlled trial. Phytomedicine. 15(9): 668-75.

Cao, X., H. Xiao and Y. Zhang. 2010. 1,5-Dicaffeoylquinic acid mediated glutathione synthesis through activation of $\mathrm{Nrf} 2$ protects against OGD/reperfusion-induced oxidative stress in astrocytes. Brain Res. 1347:142-148.

Cardarelli, M., Y. Rouphel, F. Saccardo and G. Cola. 2005. An innovative vegetative propagation system for large-scale production of globe artichokes transplants. Part I. Propagation system setup. Hortic. Technol. 15: 812-816.

Ciancolini, A., N. A. Rey, M. A. Pagnotta and P. Crino. 2012. Characterization of Italian spring globe artichoke germplasm: morphological and molecular profiles. Euphytica. 186: 433-443.

Clifford, M. 2000. Chlorogenic acids and other cinnamates-nature, occurrence, dietary burden, absorption and metabolism. J. Sci. Food Agric. 80: 1033-1043.

Coinu, R., S. Cart, P. Urgeghe, N. Mulinacci, P. Pinelli, F. Franconi and A. Romani. 2007. Dose-effect study on the antioxidant properties of leaves and outer bracts of extracts obtained from Violetto di Toscana artichoke. Food Chem. 101: 524-531.

Comino, C., A. Hehn, A. Moglia, B. Menin, F. Bourgaud, S. Lanteri and E. Portis. 2009. The isolation and mapping of a novel hydroxycinnamoyl transferase in the globe artichoke chlorogenic acid pathway. BMC Plant Biol. 9:30. 
Conti, F., G. Abbate, A. Alessandrini and C. Blasi. 2005. An annotated checklist of the Italian vascular flora. 1st ed. Palombi Ed, Roma. 428 pp.

Cravero, V. P., L. A. Picardi and E. L. Cointry 2005. An approach for understanding the heredity of two quality traits (head color and tightness) in globe artichoke (Cynara scolymus L.). Genetics and Molecular Biology. 28: 431-434.

Cravero, V., E. Martin and E. Cointry. 2007. Genetic diversity in Cynara cardunculus determined by Sequence-related Amplified Polymorphism Markers. J. Amer. Soc. Hortic. Sci. 132:1-5.

Crino, P., R. Tavazza, N.A. Rey Munoz, P. Trionfetti Nisini, F. Saccardo, G. Ancora and M.A. Pagnotta. 2008. Recovery, morphological and molecular characterization of globe artichoke 'Romanesco' landraces. Genet. Resour. Crop Evol. 55:823-833.

D’Antuono, I., A. Garbetta, V. Linsalata, F. Minervini and A. Cardinali. 2015. Polyphenols from artichoke heads (Cynara cardunculus (L.) subsp. scolymus Hayek): In vitro bio-accessibility, intestinal uptake and bioavailability. Food Funct. 6: 1268-1277.

de Falco, B., G. Incerti, M. Amato and V. Lanzotti. 2015. Artichoke: botanical, agronomical, phytochemical, and pharmacological overview. Phytochem. Rev. 14: 993-1018.

El Boullani, R., K. Lagram, A. El Mousadik and M. A. Serghini. 2017. Effect of explants density and size on the in vitro proliferation and growth of separated shoots of globe artichoke (Cynara cardunculus var. scolymus L.). J. Materials Environ. Sci. 8 (7): 2469-2473.

El-Bahr, M.K., S. A. Bekheet, A. M. Gabr, R. El-Shenawy and Y. S. El Abd. 2018. Accumulation of cynarin, the hepatoprotective compound, in ethephon treated callus cultures of globe artichoke (Cynara scolymus L.). J. Biol. Sci. 18 (5): 243-250.

Engelmann, F. 2010. Use of biotechnologies for conserving plant diversity. Acta Hortic. 812: 63-82.

Englisch, W., C. Beckers, M. Unkauf, M. Ruepp and V. Zinserling. 2000. Efficacy of artichoke dry extract in patients with hyperlipoproteinemia. Drug Res. 50: 260-265.

F.A.O. 2015. FAO Statistics Division. 6 Jan. 2015. 〈http://faostat.fao.org/site/291/default.aspx $>$.

F.A.O. 2017. Statistical Database. Available from: http://www.faostat.org/.

Fantini, N., G. Colombo, A. Giori, A. Riva, P. Morazzoni, E. Bombardelli and M.Carai. 2011. Evidence of glycemia-lowering effect by a cynara scolymus L. extract in normal and obese rats. Phytotherapy Res. 25: 463-466.

Farhan, M. M., D. S. Hassawi and N. K. Ibraheem. 2018. Callus inductions and Phytochemical Determination of Artichoke (Cynara scolymus) growing in Iraq. J. Univ. Anbar Pure Sci. 12 (2): 18-28.

Fratianni, F., M. Tucci, M. De Palma, R. Pepe and F. Nazzaro. 2007. Polyphenolic composition in different parts of some cultivars of globe artichoke (Cynara cardunculus L. var. scolymus L. Fiori). Food Chem. 104: $1282-1286$.

Fritsche, J., C. M. Beindorff and M. Dachtler. 2002. Isolation, characterization and determination of minor artichoke (Cynara scolymus L.) leaf extract compounds. Eur. Food Res. Technol. 215: 149-157.

Gális, I., Y. Kakiuchi, P. Simek and H. Wabiko. 2004. Agrobacterium tumefaciens AK-6b gene modulates phenolic compound metabolism in tobacco. Phytochemistry. 65:169-179.

Garbetta, A., I. Capotorto and A. Cardinali. 2014. Antioxidant activity induced by main polyphenols present in edible artichoke heads: influence of in vitro gastro-intestinal digestion. J. Funct. Food. 10:456-464.

García-Martínez, N., P. Andreo-Martínez and L. Almela. 2017. Characterization of six artichoke cultivars and their suitability for agro-industrial processing. J. Food Nutr. Res. 5(4): 234-242. 
Gebhardt, R. 1997. Antioxidative and protective properties of extracts from leaves of the artichoke Cynara scolymus L. against hydroperoxide-induced oxidative stress in cultured rat hepatocytes. Toxicol. Appl. Pharmacol. 144: 279-286.

Gebhardt, R. 1998. Inhibition of cholesterol biosynthesis in primary cultured rat hepatocytes by artichoke (Cynara scolymus L.) extracts. J. Pharmacol. Exp. Ther. 286:1122-112.

Gebhardt, R. 2000. Choleretic and anticholestatic activities of flavonoids of artichoke (Cynara cardunculus L. subsp. scolymus L. Hayek). Acta. Hortic. 681:429-436.

Gebhardt, R. 2001. Anticholestatic activity of flavonoids from artichoke (Cynara scolymus L.) and of their metabolites. Med. Sci. Monit. 7:316-320.

Gil-Izquierdo, A., M. I. Gil, M .A. Conesa and F. Ferreres. 2001. The effect of storage temperatures on vitamin C and phenolics content of artichoke (Cynara scolymus L.) heads. Innovative Food Sci. Emerging Technol. 2: 199-202.

Gonthier, M. P., M. A. Verny and C. Besson. 2003. Chlorogenic acid bioavailability largely depends on its metabolism by the gut microflora in rats. J. Nutr. 133:1853-1859.

Jun, N. J., K. C. Jang, S. C. Kim, D. Y. Moon, K. C. Seong, K. H. Kang, L. Tandang, P. H. Kim, K. Somi. S. K. Cho and K. H. Park. 2007. Radical Scavenging Activity and Content of Cynarin (1,3dicaffeoylquinic acid) in Artichoke (Cynara scolymus L.). J. Appl. Biol. Chem. 50(4): 244-248.

Kirchhoff, R., C. Beckers, G. M. Kirchhoff, H. Trinczek-Gartner, O. Petrowicz and H. J. Reimann. 1994. Increase in choleresis by means of artichoke extract. Phytomedicine. 1:107-115.

Kraft, K. 1997. Artichoke leaf extract recent findings reflecting effects on lipid metabolism, liver and gastrointestinal tracts. Phytomedicine. 4: 369-378.

Lanteri, S. and E. Portis. 2008. Globe artichoke and cardoon. In: Handbook of Plant Breeding. Prohens J. and Nuez F, Eds. Springer Science Business Media, New York, NY, USA. 49-74.

Lanteri, S., A. Acquadro, C. Comino and R. Mauro. 2006. A first linkage map of globe artichoke (Cynara cardunculus var. scolymus L.) based on AFLP, S-SAP, M-AFLP and microsatellite markers. Theor. Appl. Genet. 112:1532-1542.

Lanteri, S., E. Saba, M. Cadinu, G. M. Mallica, L. Baghino and E. Portis. 2004. Amplified fragment length polymorphism for genetic diversity assessment in globe artichoke. Theor. Appl. Genet. 108: 1534-1544.

Lanteri, S., I. Di Leo, L. Ledda, M. G. Mameli and E. Portis. 2001. RAPD variation within and among populations of globe artichoke cultivar "Spinoso sardo". Plant Breed. 120: 243-246.

Lattanzio, V. 2003. Bioactive polyphenols: Their role in quality and storability of fruit and vegetables. $J$. Appl. Bot. - Angewandte Botanik. 77: 128-146.

Lattanzio, V., A. Cardinali, D. Di Venere, V. Linsalata, and S. Palmieri. 1994. Browning phenomena in stored artichoke (Cynara scolymus L.) heads: Enzymic or chemical reactions? Food Chem. 50: 1-7.

Lattanzio, V., P. Kroonb, V. Linsalatac, and A. Cardinalic. 2009. Globe artichoke: A functional food and source of nutraceutical ingredients. J. Functional Foods. 1: 131-144.

Leskovar, D. I., C. Xu and S. Agehara. 2013. Planting configuration and plasticulture effects on growth, physiology, and yield of globe Artichoke. Hort. Sci. 48:1496-1501.

Llorach, R., J. C. Espin, F.A. Tomas-Barberan and F. Ferreres. 2002. Artichoke (Cynara scolymus L.) by products as a potential source of health-promoting antioxidant phenolics. J. Agr. Food Chem. 50: 34583464.

Lo Bianco, C., J. A. Ferna'ndez, D. Migliaro, P. Crino`and C. Egea-Gilabert. 2011. Identification of F1 hybrids of artichoke by ISSR markers andmorphological analysis. Mol. Breed. 27(2):157-170. 
Lombardo, S., G. Pandino, G. Mauromicale, M. Knodler, R. Carle and A. Schieber. 2010. Influence of genotype, harvest time and plant part on polyphenolic composition of globe artichoke Cynara cardunculus L. var. scolymus (L.) Fiori. Food Chem. 119:1175-1181.

Lopez-Molina, D., M. D. Navarro-Martinez, F. R. Melgarejo, N. P. Hiner, S. Chazarra and J. N. RodriguezLopez. 2005. Molecular properties and prebiotic effect of inulin obtained from artichoke (Cynara scolymus L.). Phytochem. 66: 1476-1484.

Martin, E., V. Cravero, A. Esposito, F. Lopez Anido, L. Milanesi, E. Cointry. 2008. Identification of markers linked to agronomic traits in globe artichoke. Aust. J. Crop Sci. 1:43-46.

Martino, V., N. Caffini, J. D. Phillipson, A. Lappa, A. Tchernitchin, G. Ferraro and C. Acevedo. 1999. Identification and characterization of antimicrobial components in leaf extracts of globe artichoke $(C$. scolymus L.). Acta Hortic. 501: 111-114.

Mauro, R. P., E. Portis, A. Acquadro, S. Lombardo, G. Mauromicale and S. Lanteri. 2009. Genetic diversity of globe artichoke landraces from Sicilian small-holdings: Implications for evolution and domestication of the species. Conserv. Gene. 10: 431-440.

Menin, B., A. Moglia, C. Comino, J.C. Hakkert, S. Lanteri and M.J. Beekwilder. 2013. In vitro callusinduction in globe artichoke (Cynara cardunculus L. var. scolymus) as a system for the production of caffeoylquinic acids. J. Hortic. Sci Biotech. 88: 537-542.

Menin, B., A. Moglia, C. Comino, S. Lanteri, T. W. J. M. Van Herpen and J. Beekwilder. 2012. In vitro callogenesis and Agrobacterium-mediated transformation of globe artichoke. 7th International Symposium on In Vitro Culture and Horticultural Breeding. Ghent, Belgium. Book Ser. Acta Hortic. 961:267-271.

Moglia, A., C. Comino, E. Portis, A. Acquadro, R. De Vos, J. Beekwilder and S. Lanteri. 2009. Isolation and mapping of a $\mathrm{C} 30 \mathrm{H}$ gene (CYP98A49) from globe artichoke, and its expression upon UV-C stress. Plant Cell Rep. 28:963-974.

Moglia, A., S. Lanteri, C. Comino, A. Acquadro, R. de Vos and J. Beekwilder. 2008. Stress-induced biosynthesis of dicaffeoylquinic acids in globe artichoke. J. Agr. Food Chem. 56:8641-8649.

Morello, N., G. Santoiemma, A. Ierna and G Mauromicale. 2005. Improvement of "Ovoli" production in globe artichoke by removal of the epigeal part of the plant. Acta Hortic. 681:251-6.

Morone-Fortunato, I., C. Ruta, A. Castrignanò and F. Saccardo. 2005. The effect of mycorrhizal symbiosis on the development of micropropagated artichokes. Sci. Hortic. 106 (4): 472-483.

Negro, D., S. Grieco, A. De Lisi, G. Sarli and G. Sonnante. 2011. Chlorogenic acid content variation in artichoke plant parts and physiological stages. Proc. VII IS on Artichoke, Cardoon and Their Wild Relatives Ed. C. Bazinet. Acta Hortic. 942: 469-472.

Nissler, L., R. Gebhardt and S. Berger. 2004. Flavonoid binding to a multi-drug-resistance transporter protein: an STD-NMR study. Anal. Bioanal. Chem. 379:1045-1049.

Pandino, G., F. L. Courts, S. Lombardo, G. Mauromicale and G. Williamson. 2010. Caffeoylquinic acids and flavonoids in the immature inflorescence of globe artichoke, wild cardoon and cultivated cardoon. $J$. Agri. Food Chem. 58:1026-1031.

Pandino, G., M, Meneghini, R. Tavazza, S. Lombardo and G. Mauromicale. (2017). Phytochemicals accumulation and antioxidant activity in callus and suspension cultures of Cynara scolymus L. Plant Cell. Tiss. Organ Cult.128:223-230.

Pandino, G., S. Lombardo and G. Mauromicale. 2011a. Chemical and Morphological Characteristics of New Clones and Commercial Varieties of Globe Artichoke (Cynara cardunculus var. scolymus). Plant Foods Hum. Nutr. 66: 291-297. 
Pandino, G., S. Lombardo, G. Mauromicale and G. Williamson. 2011b. Profile of poyphenols and phenolic acids in bracts and receptacles of globe artichoke (Cynara cardunculus var. scolymus), germplasm. $J$. Food Compos. Anal. 24: 148-153.

Pandino, G., S. Lombardo, G. Mauromicale and G. Williamson. 2011c. Phenolic acids and flavonoids in leaf and floral stem of cultivated and wild Cynara cardunculus L. genotypes. Food Chem. 126: 417-422.

Pandino, G., S. Lombardo, R. P. Mauro and G. Mauromicale. 2012. Variation in polyphenol profile and head morphology among clones of globe artichoke selected from a landrace. Scientia Horti. 138: 259-265.

Perez-Garcia, F., T. Adzet and S. Canigueral. 2000. Activity of artichoke leaf extract on reactive oxygen species in human leukocytes. Free Radic. Res. 33(5):661-665.

Portis, E., G. Mauromicale, R. Mauro, A. Acquadro, D. Scaglione and S. Lanteri. 2009. Construction of a reference molecular linkage map of globe artichoke (Cynara cardunculus var. scolymus). Theor. Appl. Genet. 120:59-70.

Raccuia, S. A. and M. G. Melilli. 2004. Cynara cardunculus L., a potential source of inulin in Mediterranean environment: screening of genetic variability. Aust. J. Agric. Res. 55: 693-698.

Raccuia, S. A. and M. G. Melilli. 2010. Seasonal dynamics of biomass, inulin and water soluble sugars in roots of Cynara cardunculus L. Field Crops Res. 116: 147-153.

Reed, B.M. 2008. Cryopreservation - practical consideration. In Plant Cryopreservation: A Practical Guide, pp. 3-13.

Rivelli, D .P., C. A. H. Filho, R. L. Almeida, C. D. Ropke, T.C.H. Sawada and S.B.M. Barros. 2010. Chlorogenic acid UVA-UVB photostability. Photochem. Photobiol. 86: 1005-1007.

Robinson, W. E., J. R. M. Cordeiro and S. Abdel-Malek 1996. Dicaffeoylquinic acid inhibitors of human immunodeficiency virus integrase: inhibition of the core catalytic domain of human immunodeficiency virus integrase. Mol. Pharmacol. 50(4): 846-855.

Romani, A., P. Pinelli, C. Cantini, A. Cimato and D. Heimler. 2006. Characterization of Violetto di Toscana, a typical Italian variety of artichoke (Cynara scolymus L.). Food Chem. 95: 221-225.

Rossoni, G., S. Grande and C. Galli 2005. Wild artichoke prevents the age-associated loss of vasomotor function. J. Agr. Food Chem. 53(26):10291-10296.

Rottenberg, A. 2014. The wild gene pool of globe artichoke. Israel J. Plant Scies. 62: 33-38.

Sato, Y., S. Itagaki and T. Kurokawa. 2011. In vitro and in vivo antioxidant properties of chlorogenic acid and caffeic acid. Int. J. Pharm. 403(1-2):136-13.

Scaglione, D., S. Reyes-Chin-Wo, A. Acquadro, L. Froenicke, E. Portis and C. Beitel. 2016. The genome sequence of the outbreeding globe artichoke constructed de novo incorporating a phase-aware low-pass sequencing strategy of F1 progeny. Sci. Rep. 6:19427.

Schutz, K., M. Persike, R, Carle and A. Schieber. 2006. Characterization and quantification of anthocyanins in selected artichoke (Cynara scolymus L.) cultivars by HPLC-DADESIMSn. Anal. Bioanal. Chem. 384: 1511-1517.

Sekara, A., A. Kalisz, R. Gruszeck, A. Grabowaka and E. Kunick. 2015. Globe artichoke - a vegetable, herb and ornamental of value in central Europe: A review. J. Horti. Sci. Biotec. 90 (4): 365-374.

Shimoda, H., K. Ninomiya and N. Nishida.2003. Anti-hyperlipidemic sesquiterpenes and new sesquiterpene glycosides from the leaves of artichoke (Cynara scolymus L.): structure requirement and mode of action. Bioorg. Med. Chem. Lett. 13:223-228.

Shukla, S. and S. Gupta 2010. Apigenin: a promising molecule for cancer prevention. Pharm. Res. 27(6): 962-978. 
Slanina, J., E. Táborská, H. Bochořákova, I. Slaninová, O. Humpa, W. E. Robinson and K. H. Schram. 2001. New and facile method of preparation of the anti-HIV-1 agent, 1,3-dicaffeoylquinic acid. Tetrahedron Lett. 42: 3383-3385.

Sonnante, G., A. De Paolis, V. Lattanzio and P. Perrino. 2002. Genetic variation in wild and cultivated artichoke revealed by RAPD markers. Genet. Resour. Crop Evol. 49: 247-252.

Sonnante, G., D. Pignone and K. Hammer. 2007. The domestication of artichoke and cardoon: From Roman times to the genomic age. Annal. Bot. 100: 1095-1100.

Takemura, T., T. Urushisaki and M. Fukuoka. 2012. 3,4-Dicaffeoylquinic acid, a major constituent of Brazilian propolis, increases TRAIL expression and extends the life times of mice infected with the influenza A virus. Evid Based Complement Altern. Med. 946867:1-7.

Tavazza, R., A. Lucioli, C. Benelli, D. Giorgi, E. D’Aloisio and V. Papacchioli 2013. Cryopreservation in artichoke: towards a phytosanitary qualified germplasm collection. Ann. Appl. Biol. 163: 231-241.

Tavazza, R., N. A. Rey, V. Papacchioli and M. A.Pagnotta. 2012. Monitoring of cultivar fidelity of globe artichoke germplasm in amedium-term conservation under minimal growth conditions using SSR and ISSR markers. In: Proceedings of the 56th Italian Society of Agricultural Genetics Annual Congress, Perugia, Italy, 1.21.

Trajtemberg, S. P., N. M. Apóstolo and G. Fernández. 2006. Calluses of Cynara cardunculus var. cardunculus cardoon (Asteraceae): determination of cynarine and chlorogenic acid by automated highperformance capillary electrophoresis. In Vitro Cell Dev. Biol. Plant. 42:534-537.

Vereshchagina, Y. V., V.P. Bulgakov, V. P. Grigorchuk, V. G. Rybin, G. N. Veremeichik, G. K. Tchernoded, T. Y. Gorpenchenko, O. G. Koren, N. H. T. Phan, N. T. Minh, L. T. Chau and Y. N. Zhuravle. 2014. The rolC gene increases caffeoylquinic acid production in transformed artichoke cell. Appl. Microbiol. Biotechnol. 98(18):7773-7780.

Wang, M., J. E. Simon, I. F. Aviles, K. He, Q. Zheng and Y. Tadmor. 2003. Analysis of antioxidative phenolic compounds in artichoke (Cynara scolymus L.). J. Agr. Food Chem. 51:601-608.

Welbaum, G. E. 1994. Annual culture of globe artichoke from seed in Virgiunia. Technology and Product Reports. 4 (2): 147-150.

Xiao, H. B., X. Cao and L. Wang 2011. 1,5-dicaffeoylquinic acid protects primary neurons from amyloid b142-induced apoptosis via PI3K/Akt signaling pathway. Chin. Med. J. 124: 2628-2635.

Yasukawa, K., H. Matsubara and Y. Sano. 2010. Inhibitory effect of the flowers of artichoke (Cynara cardunculus) on TPA induced inflammation and tumor promotion in two-stage carcinogenesis in mouse skin. J. Nat. Med. 64:388-391.

Zha, R. P., W. Xu and W. Y. Wang. 2007. Prevention of lipopolysaccharide-induced injury by 3,5dicaffeoylquinic acid in endothelial cells. Acta. Pharmacol. Sin. 28(8):1143-1148.

Zhu, X., H. Zhang and R. Lo. 2004. Phenolic compounds from the leaf extract of artichoke (Cynara scolymus L.) and their antimicrobial activities. J. Agr. Food. Chem. 52:7272-7278. 